\title{
Interpreting $\mathrm{Re} / \mathrm{Mo}$ ratios in sedimentary rocks
}

\author{
GEORGE R. HELZ ${ }^{1}$ \\ ${ }^{1}$ Departments of Chemistry and Geology, University of
} Maryland, College Park MD 20742 (helz@umd.edu)

Enrichment relative to crustal abundances of Re or Mo in sedimentary rocks is widely interpreted as qualitative evidence of anoxia during sedimentation. Could quantitative informaiton be extracted from these elements' abundances? Here, I explore possible information content in Re/Mo ratios. During the past $50 \mathrm{kyr}$, a period when the dissolved Re/Mo ratio in seawater is unlikely to have changed appreciably owing to these elements' long residence times, $\mathrm{EF}_{\mathrm{Re}} / \mathrm{EF}_{\mathrm{Mo}}$ ratios in marine sediments at some sites change by more than 25 -fold and display systematic secular variations. An older proposed depositional mechanism postulated that this ratio is controlled by progressive reduction, with high $\mathrm{Re} / \mathrm{Mo}$ indicative of less reducing conditions. This mechanism apppears to be inconsistent with thermochemical properties of $\mathrm{Re}$ and Mo, although the evidence is imperfect. It also fails to account for similar ranges of $\mathrm{EF}_{\mathrm{Re}} / \mathrm{EF}_{\mathrm{Mo}}$ off Vancouver Island ${ }^{1}$ and in the Arabian $\mathrm{Sea}^{2}$ despite more reducing conditions in the Arabian Sea (as judged by bottom water $\mathrm{O}_{2}$ or sediment $\mathrm{C}_{\text {org }}$ ). Here, I construct a rudimentary advection-diffusion model to explore an aletnative mechanism in which these elements are removed from seawater by coprecipitation in $\mathrm{Fe}(\mathrm{Mo}, \mathrm{Re}) \mathrm{S}_{4}$, which subsequently transforms irreversibly to $\mathrm{Fe}(\mathrm{Mo}, \mathrm{Re}) \mathrm{S}_{2}\left(\mathrm{~S}_{2}\right){ }^{3,4} \quad$ On crystal chemical grounds, this hypothesis is justified by nearly equal Mo and Re ionic radii when compared in identical oxidation states. Although Re and Mo are reduced in this mechanism, the reduction step occurs post-deposition and is not deposition controlling. Instead $\mathrm{EF}_{\mathrm{Re}}, \mathrm{EF}_{\mathrm{Mo}}$ and their ratio are all controlled by the progress of biological sulfate reduction. A partition coefficient estimated from these elements' Black Sea water column profiles suggests that in euxinic water columns Mo would be preferentially taken up in $\mathrm{Fe}(\mathrm{Mo}, \mathrm{Re}) \mathrm{S}_{4}$, but within sediment pore waters $\mathrm{Re}$ could gain a variable advantage owing to faster diffusion (because $\mathrm{ReO}_{4}^{-}$has the same size but lower charge than $\mathrm{MoO}_{4}{ }^{2-}$, its diffusion coefficient is considerably greater). Distance to the saturation horizon would modulate $\mathrm{Re} / \mathrm{Mo}$ ratios and could account for large ranges in $\mathrm{EF}_{\mathrm{Re}} / \mathrm{EF}_{\mathrm{Mo}}$ ratios as the extent of sulfate reduction in pore waters fluctuates.

1) Chang et al. (2014) Paleoceanography, 29, 730-746.

2) Van der Weijden et al. (2006) Mar. Geol. 231, 69-88.

3) Vorlicek at al. (2018) ACS Earth Space Chem. 2, 565-576.

4) Helz and Vorlicek (2019) Chem. Geol., 509, 178-193. 